\title{
Teores de chumbo e cádmio em chás comercializados na região metropolitana de Belo Horizonte
}

\author{
Irma Regina Carrara Vulcano, Josianne Nicácio Silveira, Edna Maria Alvarez-Leite* \\ Departamento de Análises Clínicas e Toxicológicas, Faculdade de Farmácia, Universidade Federal de Minas Gerais
}

*Correspondência:

E. M. Alvarez-Leite

Faculdade de Farmácia

Universidade Federal de Minas Gerais

Campus da Pampulha

Av. Antônio Carlos 6627 - sala 4136

31270-010 - Belo Horizonte - MG,

Brasil.

E-mail: alem@ufmg.br
O trabalho objetivou avaliar os niveis de chumbo e cádmio, em amostras de chás, industrializados e não-industrializados, comercializados na região metropolitana de Belo Horizonte. Foram selecionados para cada caso, dois tipos de plantas, camomila e erva-mate analisadas na forma de chá-infusão e de planta-digerida. $\mathrm{Os}$ niveis de $\mathrm{Pb}$ e $\mathrm{Cd}$ foram determinados por espectrometria de absorção atomica com forno de grafite e corretor de background Zeeman. Os niveis médios de Pb e Cd encontrados nas amostras de chá-infusão de camomila e erva-mate estavam abaixo dos valores estabelecidos pela legislação brasileira para os metais em refrescos e refrigerantes $(0,2 \mathrm{mg} / \mathrm{L})$ e as concentrações dos metais nas amostras das plantas-digeridas de camomila (valores médios de $0,15 \mu \mathrm{g} / \mathrm{g}$ para Cd e de 0,42 $\mathrm{g} / \mathrm{g}$ de Pb) e de erva-mate (valor médio de $\mathrm{Pb}$ igual a $0,53 \mu \mathrm{g} / \mathrm{g}$ ) mantiveram-se dentro das faixas consideradas como "de normalidade" pela literatura. Os niveis médios de Cd em amostras de planta-digerida de erva-mate encontrados $(2,59 \mu \mathrm{g} / \mathrm{g})$, no entanto, estavam acima dessa faixa. Não foi encontrada diferença significativa entre os niveis de Cd e Pb quantificados em amostras de chá-infusão industrializado e nãoindustrializado, tanto de camomila como de erva-mate. As concentrações dos metais nas plantas-digeridas industrializadas, tanto de camomila quanto de erva-mate, apresentam-se superiores àquelas encontradas nas plantas não industrializadas.
Unitermos

- Chás/análise qualitativa

- Chumbo/determinação

- Cádmio/determinação

- Camomila/chá/análise qualitativa

- Erva-mate/chá/análise qualitativa

\section{INTRODUÇÃO}

A contaminação de alimentos por metais pesados é uma das principais fontes de exposição humana e tem merecido atenção constante dos órgãos mundiais. Em 1976, foram criados programas para monitoramento de contaminações em alimentos sugeridos pelas diretrizes da/FAO/ WHO Expert Commitee on Food Additives (JECFA), com objetivo de conhecer e divulgar os teores de contaminantes em alimentos, assim como a contribuição destes para a con- 
taminação humana (Galal-Gorchev,1991; FAO, 2007).

A palavra chá designa vários arbustos da família das teáceas, suas folhas secas e a bebida que se obtém por infusão das mesmas. A espécie mais conhecida hoje é Camellia sinensis. Foi difundido mundialmente pela companhia Inglesa das Índias Orientais. Por extensão, são chamadas de chá as infusões de outras plantas, medicinais ou não, como a camomila e erva-mate (Nova Enciclopédia Barsa, 1999).

Conta uma lenda chinesa que o chá nasceu das pálpebras do príncipe Darma, filho de um soberano indiano. O príncipe, que fizera a promessa de viver solitário pelo resto da vida em seu jardim, velando e meditando até o nascer do sol, uma noite cansado, adormeceu. Ao acordar, desesperado, arrancou suas pálpebras e atirou-as no jardim. Essas criaram raízes, brotaram e transformaram-se num arbusto (Rohmer, 1986).

Segundo Rohmer (1986), o chá chegou ao Brasil trazido por imigrantes chineses para os Estados do Rio de Janeiro, São Paulo e Minas Gerais.

A cultura brasileira popularizou outras plantas, chamadas de chá de ervas, como chás caseiros. No interior do País, quase todos os habitantes têm uma horta com plantas consagradas pela cultura popular, como medicinais; a camomila para cólica de bebê, hortelã, capim limão ou capim cidreira como calmantes, entre outras.

O novo milênio apregoou a volta da alimentação natural, sem aditivos, e o chá de ervas passou a ser amplamente difundido e divulgado nos restaurantes naturalistas, em casas de chás e nos comércios de produtos ditos naturais. $\mathrm{O}$ mercado ficou disputado também pelas grandes indústrias que introduziram os chás prontos para consumo ou em pó solúvel. Atualmente, na maioria dos Estados brasileiros e especialmente em Minas Gerais, o uso de chás faz-se presente em todas as classes sociais e etárias, sendo as crianças, inclusive os recém-nascidos, uma parcela significativa dos consumidores, uma vez que o fato de servir chá de ervas aos mesmos é comum e bastante difundido entre as famílias das mais diversas classes sociais. Esses fatos demonstram a necessidade de ser avaliada a qualidade dos chás comercializados e utilizados no Brasil, assegurando uma composição de dieta saudável, que não acarrete risco à saúde àqueles que os utilizam.

A legislação brasileira, segundo a ANVISA, define chá, como sendo: "o produto constituído de uma ou mais partes de espécie(s) vegetal(is) inteira(s), fragmentada(s) ou moída(s), com ou sem fermentação, tostada(s) ou não, constantes de Regulamento Técnico de Espécies Vegetais para o Preparo de Chás. O produto pode ser adicionado de aroma e ou especiaria para conferir aroma e ou sabor" (Brasil, 2005).
A ANVISA estabeleceu, também, as características sensoriais, físico-químicas, microscópicas e microbiológicas, assim como os aditivos intencionais, contaminantes, ingredientes e coadjuvantes de tecnologia permitidos, e ainda a higiene, o acondicionamento, pesos e medidas além da rotulagem indicada para os chás (Brasil, 1998).

A presença de metais como chumbo e cádmio nos diversos chás de ervas ocorre, geralmente, em conseqüência da contaminação do solo por fertilizantes ou pela água de esgotos poluídos pela ação industrial ou de mineração, pelo ar atmosférico contaminado pela emissão de resíduos das grandes indústrias poluidoras ou durante a etapa de processamento dos chás, quando as espécies vegetais ficam em contato com os utensílios industriais (Han et al., 2005; Somers, 1974).

Simões et al., em 2000, apresentaram alguns critérios para avaliação da qualidade das plantas, sendo eles: existência de elementos estranhos, teor de umidade, contaminação microbiológica ou parasitária e a presença de metais pesados. Estes autores classificam como impureza, órgãos da própria planta, diferentes do farmacógeno, tais como restos de caules em flores de camomila; fragmentos de outras plantas, como gramíneas e ervas daninhas; materiais de outra origem, como areia ou terra em raízes e caules, desde que esses elementos não caracterizem falsificação ou adulteração.

O recipiente de preparo é outra causa de contaminação de chás a ser considerada. Boularbah et al., em 1998, monitoraram a migração de metais do recipiente de preparação para os chás. Estes autores simularam o preparo de chás em recipientes utilizados pela população de Marrocos, onde o uso de chá é muito difundido e observaram que a migração de metais como zinco e cobre dos vasilhames para os chás foi significativa.

Abou-Arab et al. (1999), estudando a contaminação de plantas medicinais com metais como chumbo e cádmio, concluíram que a intensidade da mesma dependerá da irrigação do solo com água contaminada ou não, do uso de fertilizantes e herbicidas durante o plantio, das espécies vegetais no caso do chumbo, da quantidade de emissão de partículas no ar, das espécies de plantas e das condições climáticas. Expõem, no trabalho, os teores que são aceitos pelas Farmacopéias Alemã e Européia: vegetais de folhas - para chumbo $0,8 \mathrm{mg} / \mathrm{kg}$ e cádmio $0,1 \mathrm{mg} / \mathrm{kg}$; frutos e raízes - chumbo $0,25 \mathrm{mg} / \mathrm{kg}$ e cádmio $0,1 \mathrm{mg} / \mathrm{kg}$.

Abou-Arab e Abou, em 2000, após a análise de várias espécies de plantas em forma de decoto e infuso, concluíram que os níveis mais elevados de contaminação por metais como o chumbo e cádmio eram encontrados no sistema radicular e nas folhas das plantas em decorrência do 
acúmulo dos metais no solo pelo uso de herbicidas e da poluição atmosférica. Observaram também que o uso de decoto resulta em maior extração dos metais para a fase aquosa do que a infusão.

Apesar de ser uma bebida com uso muito difundido no Brasil, são poucos os estudos sobre contaminação química de chás de ervas, inclusive por metais pesados. Uma avaliação sobre o conteúdo de metais em chás brasileiros foi realizada por Campos e Lima Verde Filho, em 1996, no qual vários tipos de chás foram avaliados por espectrometria de absorção atômica. Os autores estudaram os teores dos metais na infusão e no resíduo formado após o preparo da mesma, concluindo que o cádmio apresenta uma extração quantitativamente maior do que a do chumbo (Campos, Lima Filho, 1996).

A legislação brasileira também não estabelece teores permitidos de metais em chás, seja na bebida ou no resíduo das plantas.

APortaria nº 685 de 1998 da ANVISA(Brasil, 1988) alterou alguns limites estabelecidos pelo Decreto $\mathrm{n}^{\circ} 55.871$ (Brasil, 1965), que discorria sobre os índices de aditivos e contaminantes inorgânicos em alimentos, entre eles os refrescos e refrigerantes, de modo a incluir outros itens visando ao comércio com o Mercosul. O limite estabelecido para refrescos e refrigerantes no Decreto $n^{\circ} 55.871$ era de 0,2 ppm ou $0,2 \mathrm{mg} / \mathrm{L}$ e não foi alterado pela Portaria $\mathrm{n}^{\circ} 685$. A mencionada Portaria estabelece que, nos casos não contemplados por ela, devem permanecer válidos os limites já estabelecidos na legislação nacional e fixa os limites de cádmio em peixes e produtos da pesca $(1,0 \mathrm{mg} / \mathrm{kg})$ e de chumbo em vários produtos tais como: sucos de frutas cítricas $-0,3 \mathrm{mg} / \mathrm{kg}$; leite fluído pronto para consumo - $0,05 \mathrm{mg} / \mathrm{kg}$; alimentos para fins especiais, preparados especialmente para lactantes e crianças até três anos $-0,2 \mathrm{mg} / \mathrm{kg}$. A exemplo do Decreto 55.871 , a Portaria 685 também não menciona os chás.

Objetivando avaliar os teores dos metais chumbo e cádmio, em chás de camomila e erva-mate consumidos na região metropolitana de Belo Horizonte, foi elaborado o presente trabalho. Os valores encontrados foram comparados com os níveis permitidos de $\mathrm{Pb}$ e $\mathrm{Cd}$ em refrescos e refrigerantes uma vez que, como explicitado anteriormente, a legislação brasileira não estabelece os teores permitidos de metais em chás.

\section{MATERIAL E MÉTODOS}

\section{Amostragem}

As amostras para a realização do trabalho foram adquiridas na região metropolitana de Belo Horizonte, a saber: chás vendidos em ervanários, empacotadas pelos próprios comerciantes (considerados, nesse trabalho, como não-industrializados) e chás processados industrialmente e comercializados na região (considerados chás industrializados).

As amostras foram, então, classificadas em:

Grupo 1.I $(n=14)$ : amostras de chá industrializado de camomila, Grupo 1.N (n=6): amostras de chá não-industrializado de camomila, Grupo 2.I $(\mathrm{n}=15)$ : amostras de chá industrializado de erva-mate, Grupo 2.N (n=6): amostras de chá não industrializado de erva-mate .

Os níveis de chumbo e cádmio foram determinados nas amostras de chá preparadas pelo método de infusão (chá-infusão ou infusão) e nas plantas após processo de digestão ácida (planta-digerida ou digerido), o que determinou a subdivisão de cada grupo de amostras em dois subgrupos, o subgrupo i referindo-se aos chás preparados como infusão e o subgrupo d relatado ao digerido da planta.

\section{Preparo do chá-infusão}

Amostra de $1 \mathrm{~g}$ de planta seca foi adicionada a $50 \mathrm{~mL}$ de água Milli-Q ${ }^{\circledR}$ fervente e deixada em maceração por 15 minutos. Após este tempo, o chá foi filtrado em peneira de polietileno, e adicionado de volume suficiente de ácido nítrico Merck ${ }^{\circledR}$ suprapur para se obter um chá com 0,6\% de ácido (Anderson, 1999).

\section{Preparo da planta-digerida}

Amostra de 0,25 g da planta seca foi transferida para tubos de vidro com condensador de refluxo e adicionadas de $1,5 \mathrm{~mL}$ de ácido nítrico. Os tubos foram deixados em repouso por $1 / 2$ hora à temperatura ambiente e, em seguida, aquecidos entre 170 a $180^{\circ} \mathrm{C}$ por 1,5 a 2 horas para completar a digestão. $\mathrm{O}$ volume foi completado para $10 \mathrm{~mL}$ com água Milli- $\mathrm{Q}^{\oplus} \mathrm{e}$, em seguida, os tubos foram centrifugados a $3500 \mathrm{rpm}$ por 10 minutos e os sobrenadantes separados para a análise dos metais. Para a determinação de cádmio as amostras digeridas foram, ainda, diluídas de 1:10 antes da análise (Anderson, 1999).

\section{Determinação dos metais}

Os teores de $\mathrm{Pb}$ e $\mathrm{Cd}$ foram determinados nas amostras de chá infusão e planta-digerida de camomila e ervamate, por espectrometria de absorção atômica com forno de grafite, equipado com injetor automático e corretor de fundo para efeito Zeeman $\left(\operatorname{Varian}^{\circledR}\right.$, modelo Spectr AA Zeeman 220), empregando-se plataformas L'Vov tratadas com o modificador permanente irídio (irídio em $1 \mathrm{~mol} / \mathrm{L}$ de $\mathrm{HCl}$ ) (Silva et al., 1998). 
O método foi previamente validado e os seguintes parâmetros de méritos foram estabelecidos: linearidade, limite de quantificação, precisão e efeito matriz.

$\mathrm{O} \mathrm{HNO}_{3}$ a $0,6 \%$ foi empregado como modificador em solução nas determinações do cádmio. No método de análise do chumbo foram empregados $\mathrm{NH}_{4} \mathrm{H}_{2} \mathrm{PO}_{4}$ a $1,2 \%$, $\mathrm{Mg}\left(\mathrm{NO}_{3}\right)_{2}$ a $0,3 \%$ e $\mathrm{HNO}_{3}$ a $0,6 \%$ como modificador em solução.

O estudo estatístico para comparar os teores dos metais em função da procedência e do tipo de preparo das amostras foi realizado empregando-se o teste t de Student, aceitando-se como significativo o valor $\mathrm{p}<0,05$ (software estatístico SigmaStat ${ }^{\circledR}$ for Windows 2:0, da Jandel Corporation).

\section{RESULTADOS E DISCUSSÃO}

As condições operacionais que forneceram uma adequada sensibilidade analítica e uma perfeita separação entre os picos de absorção dos metais de interesse, cádmio e chumbo, e os picos de absorção não-atômica foram: resolução espectral-0,5 nm; corrente da lâmpada- 5,0 mA; modo do instrumento- absorvância; modo de medida- área de pico; modo de calibração- linear pela origem. Os comprimentos de onda utilizados foram $228,8 \mathrm{~nm}$ para o cádmio e 283,3 nm para o chumbo. No caso da determinação de $\mathrm{Pb}$ o aparelho foi programado para o modo de multinjeção, quando 3 alíquotas de $13,0 \mu \mathrm{L}$ das amostras e dos padrões foram tomadas antes do início da leitura.

Optou-se em trabalhar com plataformas L'Vov, uma vez que elas retardam a vaporização do metal até que o tubo atinja uma alta temperatura de estabilização, minimizando assim as interferências na fase da atomização de vapor. As plataformas foram tratadas com irídio (irídio em $1 \mathrm{~mol} / \mathrm{L}$ de $\mathrm{HCl}$ ) um modificador permanente que tem se mostrado eficiente no aumento da vida-útil das mesmas (Silva et al., 1998).

TABELA I - Valores médios, desvios padrão, média geométrica e faixa de variação dos níveis de Cd em amostras de cháinfusão e de planta-digerida de camomila e erva-mate

\begin{tabular}{lccccc}
\hline Planta & Subgrupo & Valores de min.-máx. & Desvio padrão & Valor médio & Média geométrica \\
\hline camomila & 1.I.i $(\mathrm{n}=14)$ & $0,2-0,6 \mu \mathrm{g} / \mathrm{L}$ & $\pm 0,2$ & $0,4 \mu \mathrm{g} / \mathrm{L}$ & $0,4 \mu \mathrm{g} / \mathrm{L}$ \\
(grupo 1) & 1.I.d $(\mathrm{n}=13)$ & $0,14-0,3 \mu \mathrm{g} / \mathrm{g}$ & $\pm 0,04$ & $0,2 \mu \mathrm{g} / \mathrm{g}$ & $0,2 \mu \mathrm{g} / \mathrm{g}$ \\
& 1.N.i. $(\mathrm{n}=6)$ & $0,2-0,6 \mu \mathrm{g} / \mathrm{L}$ & $\pm 0,2$ & $0,4 \mu \mathrm{g} / \mathrm{L}$ & $0,4 \mu \mathrm{g} / \mathrm{L}$ \\
& 1.N.d (n=6) & $0,1-0,2 \mu \mathrm{g} / \mathrm{g}$ & $\pm 0,04$ & $0,14 \mu \mathrm{g} / \mathrm{g}$ & $0,14 \mu \mathrm{g} / \mathrm{g}$ \\
\hline erva-mate & 2.I.i $(\mathrm{n}=15)$ & $0,6-4,6 \mu \mathrm{g} / \mathrm{L}$ & $\pm 1,2$ & $1,4 \mu \mathrm{g} / \mathrm{L}$ & $1,0 \mu \mathrm{g} / \mathrm{L}$ \\
(grupo 2) & 2.I.d (n=14) & $1,7-4,0 \mu \mathrm{g} / \mathrm{g}$ & $\pm 0,6$ & $3,1 \mu \mathrm{g} / \mathrm{g}$ & $3,0 \mu \mathrm{g} / \mathrm{g}$ \\
& 2.N.i (n=6) & $0,6-0,1 \mu \mathrm{g} / \mathrm{L}$ & $\pm 0,8$ & $1,4 \mu \mathrm{g} / \mathrm{L}$ & $1,3 \mu \mathrm{g} / \mathrm{L}$ \\
& 2.N.d (n=6) & $0,3-3,6 \mu \mathrm{g} / \mathrm{g}$ & $\pm 1,6$ & $1,4 \mu \mathrm{g} / \mathrm{g}$ & $0,7 \mu \mathrm{g} / \mathrm{g}$ \\
\hline
\end{tabular}

O estudo do efeito da matriz foi positivo determinando que as curvas de linearidade e de calibração fossem preparadas em chá-infusão e planta-digerida, conforme o caso.

A linearidade foi calculada empregando-se o método de adição de padrão do equipamento. Por esse método, a linearidade foi mantida, para o $\mathrm{Cd}$, até a concentração de $1,2 \mu \mathrm{g} / \mathrm{L}$ e para o $\mathrm{Pb}$ até $60,0 \mu \mathrm{g} / \mathrm{L}$. As faixas de trabalho selecionadas (curva de calibração) foram, para o Cd: de 0,2 a $1,2 \mu \mathrm{g} / \mathrm{L}$ e para o $\mathrm{Pb}: 1,0$ a $30,0 \mu \mathrm{g} / \mathrm{L}$.

Os limites de quantificação dos métodos validados (LQ), calculados como sendo a menor concentração da curva de calibração que apresentou precisão dentro do coeficiente de variação interensaio médio estabelecido foram $0,2 \mu \mathrm{g} / \mathrm{L}$ para o $\mathrm{Cd}$ e $1,0 \mu \mathrm{g} / \mathrm{L}$ para o $\mathrm{Pb}$.

A precisão dos métodos expressa como coeficiente de variação interensaio médio variou de $5,6 \%$ a $8,3 \%$ para $\mathrm{Cd}$ e de 5,1 a 9,2\% para o $\mathrm{Pb}$ (chá infusão e planta digerida, respectivamente).

Os valores de $\mathrm{Cd}$ e $\mathrm{Pb}$ nos grupos e subgrupos analisados foram tratados estatisticamente e estão apresentados, de forma compilada, nas Tabelas I e II.

Foram calculados, também, os teores de cádmio e chumbo em todas as preparações de infusão e de plantadigerida das amostras de chá de camomila e de erva-mate, independentemente da procedência dos mesmos (Tabela III).

Como citado anteriormente, a legislação brasileira não estabelece níveis permitidos de metais em chás, apenas em refrescos e refrigerantes $(0,2 \mathrm{mg} / \mathrm{L})$. Pelos dados apresentados nas Tabelas I e II, observa-se que as concentrações médias de cádmio e de chumbo nas amostras de cháinfusão, tanto de camomila quanto de erva-mate, estão muito abaixo do permitido pela legislação brasileira para refrescos e refrigerantes.

Em relação aos teores de metais na planta-digerida, destaca-se o elevado teor de cádmio encontrado nas amos- 
TABELA II - Valores médios, desvios padrão, média geométrica e faixa de variação dos níveis de Pb em amostras de cháinfusão e planta-digerida de camomila e erva-mate

\begin{tabular}{lccccc}
\hline Planta & Subgrupo & Valores de min.-máx. & Desvio padrão & Valor médio & Média geométrica \\
\hline camomila & 1.I.i (n=14) & $1,4-7,0 \mu \mathrm{g} / \mathrm{L}$ & $\pm 1,8$ & $4,4 \mu \mathrm{g} / \mathrm{L}$ & $4,4 \mu \mathrm{g} / \mathrm{L}$ \\
(grupo 1) & 1.I.d (n=14) & $0,3-0,8 \mu \mathrm{g} / \mathrm{g}$ & $\pm 0,2$ & $0,5 \mu \mathrm{g} / \mathrm{g}$ & $0,5 \mu \mathrm{g} / \mathrm{g}$ \\
& 1.N.i (n=6) & $2,0-4,0 \mu \mathrm{g} / \mathrm{L}$ & $\pm 2,0$ & $2,0 \mu \mathrm{g} / \mathrm{L}$ & $2,8 \mu \mathrm{g} / \mathrm{L}$ \\
& 1.N.d (n=6) & $0,3-0,4 \mu \mathrm{g} / \mathrm{g}$ & $\pm 0,1$ & $0,3 \mu \mathrm{g} / \mathrm{g}$ & $0,3 \mu \mathrm{g} / \mathrm{g}$ \\
\hline erva-mate & 2.I.i (n=15) & $1,0-7,4 \mu \mathrm{g} / \mathrm{L}$ & $\pm 1,8$ & $3,0 \mu \mathrm{g} / \mathrm{L}$ & $2,6 \mu \mathrm{g} / \mathrm{L}$ \\
(grupo 2) & 2.I.d (n=15) & $0,4-1,5 \mu \mathrm{g} / \mathrm{g}$ & $\pm 0,3$ & $0,7 \mu \mathrm{g} / \mathrm{g}$ & $0,6 \mu \mathrm{g} / \mathrm{g}$ \\
& 2.N.i (n=6) & $1,4-2,4 \mu \mathrm{g} / \mathrm{L}$ & $\pm 0,4$ & $2,0 \mu \mathrm{g} / \mathrm{L}$ & $2,0 \mu \mathrm{g} / \mathrm{L}$ \\
& 2.N.d (n=6) & $0,3-0,6 \mu \mathrm{g} / \mathrm{g}$ & $\pm 0,1$ & $0,4 \mu \mathrm{g} / \mathrm{g}$ & $0,4 \mu \mathrm{g} / \mathrm{g}$ \\
\hline
\end{tabular}

TABELA III - Valor médio e desvio padrão das concentrações de $\mathrm{Cd}$ e Pb em preparações de infusão e planta-digerida das amostras de chá de camomila e de erva-mate, independente da procedência dos mesmos

\begin{tabular}{lccccc}
\hline metal & \multicolumn{2}{c}{ camomila } & & \multicolumn{2}{c}{ erva-mate } \\
\cline { 2 - 3 } \cline { 5 - 6 } & infusão $(\mu \mathrm{g} / \mathrm{L})$ & digerido $(\mu \mathrm{g} / \mathrm{g})$ & & infusão $(\mu \mathrm{g} / \mathrm{L})$ & digerido $(\mu \mathrm{g} / \mathrm{g})$ \\
\hline $\mathrm{Cd}$ & $0,4 \pm 0,02$ & $0,2 \pm 0,03$ & & $1,4 \pm 1,0$ & $2,6 \pm 1,4$ \\
$\mathrm{~Pb}$ & $3,2 \pm 1,6$ & $0,4 \pm 0,11$ & & $1,8 \pm 0,10$ & $0,5 \pm 0,3$ \\
\hline
\end{tabular}

tras de erva-mate, tanto nas amostras industrializadas quanto nas não-industrializadas, valores estes muito superiores aos obtidos em estudos semelhantes citados na literatura. Estando os teores de cádmio elevados nas plantas-digeridas seria de se esperar que as concentrações deste metal nas amostras de chá-infusão correspondentes estivessem igualmente elevadas e isto não ocorreu. Embora o elevado teor de cádmio encontrado nas plantasdigeridas de erva-mate seja preocupante, é necessário considerar o número de amostras analisadas nos subgrupos 2.I.d. $(\mathrm{n}=14)$ e 2.N.d $(\mathrm{n}=6)$, demonstrando a necessidade de amostragem maior e mais diversificada para verificar a real qualidade das plantas de erva-mate comercializadas na região.

Em 1999 e 2000, foram realizadas pesquisas no Egito, buscando determinar por espectrometria de absorção atômica com forno de grafite, os níveis de metais (cádmio e chumbo) em amostras de chá de camomila a granel e em amostras empacotadas, o que poderia corresponder, respectivamente, às amostras não-industrializadas e industrializadas analisadas no presente trabalho (Abou-Arab et al., 1999, 2000). Os autores encontraram teores de $\mathrm{Pb}$ de $0,242 \mu \mathrm{g} / \mathrm{g}$ e $0,308 \mu \mathrm{g} / \mathrm{g}$, respectivamente nas amostras de chás empacotados e a granel. Para o cádmio os níveis encontrados foram de $0,094 \mu \mathrm{g} / \mathrm{g}$ (empacotados) e $0,211 \mu \mathrm{g} / \mathrm{g}$ (a granel). Estes autores consideram ainda, que os valores de chumbo estavam elevados e atribuí- ram o fato a possível contaminação das amostras pela poluição do ar, do solo, da água de irrigação, uso de herbicidas e de fertilizantes. Comparando estes resultados com os obtidos nos subgrupos I.d e N.d, tanto no grupo 1 quanto no grupo 2 (Tabela III), observa-se que os teores de chumbo e de cádmio, no presente trabalho, foram superiores aos detectados por Abou-Arab et al., 1999.

Onianwa et al. (1999), analisando metais em amostras de chá (pó), determinaram valores de 0,06-0,28 $\mu \mathrm{g} / \mathrm{g}$ para o $\mathrm{Cd}$ e $0,16-1,32 \mu \mathrm{g} / \mathrm{g}$ para o $\mathrm{Pb}$. A análise realizada no chá (bebida) detectou $0,98 \mu \mathrm{g} / \mathrm{L}$ de Cd e $3,8 \mu \mathrm{g} / \mathrm{L}$ de $\mathrm{Pb}$. Embora os autores não tenham especificado o tipo e a procedência dos chás analisados, buscou-se comparar esses resultados com aqueles expressos na Tabela III do presente trabalho, ou seja, $0,4 \mu \mathrm{g} / \mathrm{L} \mathrm{e} 1,4 \mu \mathrm{g} / \mathrm{L}$ para $\mathrm{Cd}$ em camomila e em erva-mate e de $3,2 \mu \mathrm{g} / \mathrm{L}$ e $1,8 \mu \mathrm{g} / \mathrm{L}$ para o $\mathrm{Pb}$ também em camomila e erva-mate, respectivamente. Verifica-se que, com exceção do Cd no chá-infusão e planta-digerida de erva-mate, os demais níveis dos metais quantificados mantiveram-se dentro ou abaixo da faixa de concentração encontrada pelos autores.

Campos e LimaVerde Filho (1996) propuseram faixas de concentrações consideradas como "de normalidade" e "excessiva" para cádmio e chumbo em amostras de diferentes plantas. Segundo esses autores, a faixa "de normalidade" para os teores de Cd seria de 0,05 a $0,2 \mu \mathrm{g} / \mathrm{g}$ e a 
"excessiva" de 5 a $30 \mu \mathrm{g} / \mathrm{g}$. Para o chumbo a "de normalidade" estaria entre 5 a $10 \mu \mathrm{g} / \mathrm{g}$ e a excessiva variando de 30 a $300 \mu \mathrm{g} / \mathrm{g}$. Comparando-se as faixas propostas pelos autores, com os valores encontrados, na presente pesquisa, nas amostras de planta-digerida (Tabelas I, II, III), podese concluir que, independente da procedência das amostras, os teores de chumbo encontrado nas plantas-digeridas de camomila e erva-mate e os de cádmio nas de camomila, podem ser incluídos na faixa "de normalidade". As concentrações de cádmio nas plantas-digeridas de erva-mate estão acima dos valores considerados como "faixa de normalidade" sem atingir, entretanto, a faixa de concentração tida como "excessiva" pelos autores.

Os dados acima apresentados permitem constatar que os teores de chumbo nas amostras de chá de camomila e de erva-mate, tanto nas infusões quanto nas plantas-digeridas, foram inferiores aos teores encontrados na literatura exceção feita àqueles citados por Abou-Arab et al. (1999). Esta mesma constatação pode ser feita em relação aos teores de cádmio nos chás-infusão de camomila e erva-mate e nas plantas-digeridas de camomila, mas não nas de erva-mate.

Um estudo estatístico objetivando comparar os teores dos metais em função da procedência e do tipo de preparo das amostras foi realizado empregando-se o teste $t$ de Student e aceitando-se como significativo o valor $p<0,05$. Os resultados indicam uma diferença significativa entre os valores de cádmio e de chumbo quando são comparadas as amostras de plantas-digeridas e as de chá-infusão. Os níveis dos dois metais, tanto para a camomila quanto para erva-mate, foram sempre superiores nas plantas-digeridas, o que poderia decorrer da pequena solubilidade do cádmio e chumbo em água.

Comparando-se os teores de cádmio e chumbo nas amostras industrializadas e não-industrializadas de cháinfusão, observa-se a inexistência de diferença significativa entre eles, tanto na camomila quanto na erva-mate. O oposto foi observado quando os teores dos metais na plantadigerida foram comparados. As concentrações de cádmio e chumbo foram sempre superiores nas amostras industrializadas do que nas não-industrializadas. Estas diferenças foram significativas $(p<0,05)$ com exceção da encontrada para os valores de chumbo em erva-mate.

Procurou-se avaliar, ainda, pelo teste $t$ de Student, se os teores de cádmio e de chumbo seriam diferentes em função do tipo de chá analisado. O teste mostrou que a concentração de cádmio nas infusões e nas plantas-digeridas de erva-mate, tanto nos chás industrializados quanto nos nãoindustrializados (Tabela I), eram significativamente maiores do que aqueles encontrados na camomila. O resultado dessa comparação, entretanto, não se apresentou homogêneo no caso do chumbo.
A interpretação destes dados torna-se difícil, uma vez que os chás de erva-mate e de camomila foram adquiridos de fabricantes diferentes e sem informações referentes ao cultivo das plantas, tais como o local da plantação, tipo de solo, uso de praguicidas, tratamento das folhas colhidas, entre outras. É desejável, portanto, que a presente pesquisa seja continuada com uma amostragem maior e com o detalhamento de fatores e características referentes à procedência e ao cultivo das plantas.

\section{ABSTRACT}

\section{Lead and cadmium levels in tea traded in the metropolitan area of Belo Horizonte}

This research aims at evaluating the levels of lead and cadmium in industrialized and non-industrialized samples of tea traded in the metropolitan area of Belo Horizonte, due to the constant use of different kinds of tea by the Brazilians. Camomile and maté have been selected and analyzed as teainfusion and digested-plant. The levels of $\mathrm{Pb}$ and $\mathrm{Cd}$ were determined by spectrometry of atomic absorption with graphite furnace and Zeeman background corrector. The average levels of $\mathrm{Pb}$ and $\mathrm{Cd}$ in samples of camomile and maté tea-infusion were below the values established by the Brazilian legislation for metals in soft drinks $(0.2 \mathrm{mg} / \mathrm{L})$. The concentrations of metals in plant-digested camomile samples $(0.15 \mu \mathrm{g} / \mathrm{g}$ to $\mathrm{Cd}$ and $0.42 \mu \mathrm{g} / \mathrm{g}$ to $\mathrm{Pb}$ ) and plant-digesgted mate samples $(0.53 \mu \mathrm{g} / \mathrm{g})$ were considered normal according to the literature with exception of Cd levels in plant-digested maté samples $(2.59 \mu \mathrm{g} / \mathrm{g})$. Difference was not found significant between the levels of quantified $\mathrm{Cd}$ and $\mathrm{Pb}$ in samples of industrialized and not industrialized tea-infusion camomile and maté teas. The concentrations of metals were higher in industrialized digested-plant camomile and maté, when compared with not industrialized. There was no significant difference among tea-infusion samples.

UNITERMS: Tea/qualitative analysis. Lead/determination. Cadmium/determination. Camomile/tea/qualitative analysis. Maté/tea/qualitative analysis.

\section{REFERÊNCIAS BIBLIOGRÁFICAS}

ABOU-ARAB, A.A.K.; KAWTHER, M.S; EL TANTAWY, F.; ISMAEL, B.R; KHAYRIA, N. Quantity estimation of some contaminants in commonly used medical plants in the Egyptian market. Food Chem., v.67, p.357-363, 1999. 
ABOU-ARAB, A.A.K.; ABOU, D.M.A. Heavy metals in Egyptian spices and medical plants and the effect of processing on their levels. J. Agric. Food Chem., v. 48, p.2300-2304, 2000.

ANDERSON, K.A. Analytical techniques for inorganic contaminants. Gaithersburg: AOAC International, 1999. $316 \mathrm{p}$.

BRASIL. Resolução de Diretoria Colegiada-RDC nº 277 , de 22 de setembro de 2005. AAgência Nacional de Vigilância Nacional aprova o "Regulamento Técnico para café, cevada, chá, erva-mate e produtos solúveis" . Anexo: Regulamento Técnico para café, cevada, chá, mate e produtos solúveis. 2005. Diário Oficial da União, Poder Executivo, de 23 de setembro de 2005. Disponível em: $<$ http://e-legis.anvisa.gov.br/leisref/public/ showAct.php?id=18837\&word=caf\%C3\%A9>. Acesso em: 01 jun. 2007.

BRASIL. Portaria ${ }^{\circ} 685$ de 27 de agosto de 1998. AAgência Nacional de Vigilância Sanitária aprova o Regulamento Técnico: "Princípios Gerais para o Estabelecimento de Níveis Máximos de Contaminantes Químicos em Alimentos" e seu Anexo: "Limites máximos de tolerância para contaminantes inorgânicos". Diário Oficial da União, Brasília; Poder Executivo, de 28 de agosto de 1998. Disponível em: <http://e-legis.anvisa.gov.br/leisref/ public/showAct.php?id=90\&word=alimentos $>$. Acesso em: 14 jun. 2007

BOULARBAH, A.; BITTON, G.; MOREL, J.L. Assessment of metal content and of leachates from teapots. Sci. Total Environ., v.227, p.69-72, 1998.

BRASIL Decreto n ${ }^{\circ} 55.871$, de 26 de março de 1965. Modifica o Decreto ${ }^{\circ} 50.040$, de 24 de janeiro de 1961, referente a normas reguladoras do emprego de aditivos para alimentos, alterado pelo Decreto $\mathrm{n}^{\circ} 691$, de 13 de março de 1962. Diário Oficial da União; Poder Executivo, de 09 de abril de 1965. Disponível em: <http://elegis.bvs.br/leisref/public/showAct.php?id=22>. Acesso em: 01 out. 2007.
CAMPOS, R.C.; LIMAVERDE FILHO, A.M. Avaliação do conteúdo de metais em plantas de uso na medicina popular e em seus extratos aquosos. Ciênc. Tecnol. Aliment., v.16, p.184-187, 1996.

NOVA ENCICLOPÉDIA BARSA. Chá: 1999. CD-CDV 111. Produzido pela Encyclopaedica Britannica do Brasil Publicações.

GALAL-GORCHEV, H. Dietary intake of pesticide residues: cadmium, mercury, and lead. Food Addit. Contam., v.8, p.793-806, 1991.

HAN W.Y.; SHI YZ, M.A.L.F.; RUAN, J.Y. Arsenic, cadmium, chromium, cobalt, and copper in different types of Chinese tea. Bull. Environ. Contam. Toxicol., v.75, p.272-277, 2005.

FOOD AND AGRICULTURE ORGANIZATION OF THE UNITED NATIONS; WORLD HEALTH ORGANIZATION-FAO/WHO. Summary of Evaluations Performed by the Joint FAO/WHO Expert Committee on Food Additives (JECFAA 1956-2007). Disponível em: $<$ http://jecfa.ilsi.org/section1.htm\#41>. Acesso em: 03 out. 2007.

ONIANWA P.C.; ADETOLA, I.G.; IWEGBUE, C.M.A.; OJO, M.F.; TELLA, O.O. Trace heavy metals composition of some Nigerian beverages and foods drinks. Food Chem., v.66, p.275-279, 1999.

ROHMER F. O livro do chá. São Paulo: Ground, 1986. 102p.

SILVA, J.B.B.; GIACOMELLI, M. B. O.; SOUZA, I. G.; CURTIS, A. J. Iridium and rhodium as permanent chemical modifiers for the determination of $\mathrm{Ag}, \mathrm{As}, \mathrm{Bi}, \mathrm{Cd}$, and $\mathrm{Sb}$ by electrothermal atomic absorption spectrometry. Microchem. J., v.60, p.249-257, 1998.

SIMÕES, C.M.O.; SCHENKEL, E.P.; GOSMAN, G.; MELLO, J.C.P.; MENTZ, L.A.; PETROVICK, P.R. Farmacognosia: da planta ao medicamento. 2.ed. Porto Alegre: Editora UFRGS, 2000. 860p.

SOMERS, E. The toxic potencial of trace metals in food. A review. J. Food Sci., v.39, p.215-217, 1974.

Recebido para publicação em 25 de junho de 2007 Aceito para publicação em 27 de março de 2008 